\title{
A Two-phase Model of Air Shock Wave Induced by Rock-fall
}

\section{in Closed Goaf}

\author{
Fengyu Ren ${ }^{1}$, Yang Liu ${ }^{1 *}$, Jianli $\mathrm{Cao}^{1}$, Rongxing $\mathrm{He}^{1}$, Yuan $\mathrm{Xu}^{1}$, \\ Xi You ${ }^{1}$, Yanjun Zhou ${ }^{1}$ \\ ${ }^{1}$ School of Resources and Civil Engineering, Northeastern University, Shenyang, \\ Liaoning Province, China \\ ${ }^{*}$ Correspondence: liuyang1510448@gmail.com; Tel: +86-24-83678401
}

\begin{abstract}
In this paper, a two-phase model of air shock wave induced by rock-fall was described. The model was made up of the uniform motion phase (velocity was close to $0 \mathrm{~m} \cdot \mathrm{s}^{-1}$ ) and the acceleration movement phase. The uniform motion phase was determined by experience, meanwhile the acceleration movement phase was derived by the theoretical analysis.A series of experiments were performed to verify the twophase model and obtained the law of the uniform motion phase. The acceleration movement phase was taking a larger portion when height of rock-fall was higher with the observations. Experimental results of different falling heights showed good agreements with theoretical analysis values. Computational fluid dynamics (CFD) numerical simulation had been carried out to study the variation velocity with different falling height. The two-phase model could provide a reference and basis for estimating the air shock waves' velocity and designing the protective measures.
\end{abstract}

Keywords: air shock wave; rock-fall; two-phase model; computational fluid dynamics (CFD). 


\section{Introduction}

In recent years, the failures of rock-roof and the collapse of surface are more frequent which severely damages to people and mining [1-3]. In these mine disasters, the air shock wave is one of typical forms with the characteristic of high velocity, high pressure, huge impact force and short application time[4-6]. With the purpose of reducing the damage of this disaster, various models have been built to predict the velocity of the air shock wave[7-9]. However, the accuracy of these models is still less than the true value of the air shock waves' velocity.

Experimental research — the most common method — can not only obtain the true value of the air shock waves' velocity, but also can analyze the influencing factors of rock-fall height. To that end, Janovsky et al. [10] used methane and air as the tested material to analyze the velocity and their impact on 14 and $29 \mathrm{~cm}$ thick walls in the process of exploration. Mixture air have also been adopted as pure air in many experiments [11-13]. Xing et al. [14] revealed complex influences of goaf with different collapse areas on the velocity and pressure of the air shock wave in different mining faces. Pennetier et al. [15] performed experiments of the air shock flushing the outlet tunnel and presented evolution of the pressures and velocities of both the inlet and outlet tunnel in detail with the measurements on different blasted volume. Moreover, test instruments used in experiments were not the same, such as thermal anemometer [16], different-pressure anemometer[17], ultrasonic anemometer[18]. Ovink et al. [19] used the hot wire hot film Anemometer as a test instrument to study the results acting conform to the actual values during travel over experimental material.

In numerical simulation, gas flows usually can be modeled by computational fluid dynamics (CFD) - mainly two approaches-Euler-Euler [20-23] and Euler- 
Lagrange [24-27]. In Lagrangian approach, gas flows have been given to the direct physical interpretation and analyzed by Lagrangian forms continuity and momentum equation. Euler-Euler CFD simulations as a common numerical method have been widely applied to the simulations of gas flows [28-30]. Zhu et al. [31] modeled 3D gas flows using Euler-Euler CFD simulation. Despite 3D models [32, 33] were more precise than 2D ones [34,35], 2D models could still provide enough information and save time tremendously. Thus, in the case where the flow regime was not complex, a 2D model could be used to understand expecting results[36]. Spicka et al. [37] presented a numerical simulation of gas flows by a two-phase model using $2 \mathrm{D}$ model in the nuclear and car industries. The results show good agreement between experimental values and simulation values. Furthermore, combination of CFD and user defined function (UDF) [38] has been carried out. Qin et al [39] used CFD and UDF to simulate small-scale experiments which better define movement forms and properties of mixture gas.

In this paper, we presented a two-phase model for air shock wave induced by rock-fall in closed goaf. Specifically, the model was composed of the uniform motion phase and the acceleration movement phase. The uniform motion phase was determined by experience, and the acceleration movement phase was derived by theoretical analysis. Then a series of experiments were conducted to verify two-phase model and obtained the law of the uniform motion phase, and CFD and UDF were used to stimulate the experiments by $2 \mathrm{D}$ models. Finally, we evaluated the effectiveness of our model and compared its performance with experimental and numerical simulation values. 


\section{Modeling Description}

\subsection{Basic Assumptions}

Based on the model of pump [7] and streaming [8], a model of two-phase was raised to estimate air shock wave induced by rock-fall. The model was composed of the uniform motion phase and the acceleration movement phase. The speed of the uniform motion phase was close to $0 \mathrm{~m} \cdot \mathrm{s}^{-1}$ on account of the pressure difference. The acceleration movement phase was derived by computational fluid mechanics and classical mechanics. Then, the following assumptions were raised:

(a) Air was considered ideal gas and characterized by laminar flow conditions;

(b) The process of air shock wave was identified as an isothermal process;

(c) The goaf was considered as closed and the volume difference of it was neglected.

\subsection{Modeling Equations}

The governing equations were used in our $2 \mathrm{D}$, isothermal model would be described. The law of conservation of momentum [40,41] is shown as follows:

$$
\rho\left(\frac{\partial v_{i}}{\partial t}+v_{j} \frac{\partial v_{i}}{\partial x_{j}}\right)=\rho F_{i}-\frac{\partial p}{\partial x_{i}}-\frac{2}{3} \frac{\partial}{\partial x_{i}}\left(\mu \frac{\partial v_{j}}{\partial x_{j}}\right)+\frac{\partial}{\partial x_{j}}\left(\mu\left(\frac{\partial v_{i}}{\partial x_{j}}+\frac{\partial v_{j}}{\partial x_{i}}\right)\right)
$$

Where $F$ is the body force, $(N) ; \mu$ is the viscosity of air, $(\mathrm{Pa} \cdot s)$.

As results of the above assumptions, values for $\mu$ is 0 and $\rho$ is got from the ideal law, $\rho=p / R T$, which $R$ is the universal gas constant and $T$ is the absolute temperature respectively. The weight of falling roof was acted as the body force. Eq. (1) is simplified as:

$$
\frac{\partial v_{z}}{\partial z}=g-\frac{p_{n}-p_{n-1}}{\rho_{d} N}
$$


Where $\rho_{d}$ is the density of the rock-fall, $\left(\mathrm{kg}^{\circ} \mathrm{m}^{-3}\right) ; N$ is thickness of the rock-fall, $(\mathrm{m})$; $p n$ is the pressure of the former, $(\mathrm{Pa}) ; \mathrm{pn}-1$ is the pressure of the latter, $(\mathrm{Pa})$.

In our model, the ideal gas state equation [41] is described:

$$
p_{n} V_{n}=p_{n-1} V_{n-1}
$$

Where $V n$ is the falling volume of the latter, $\left(m^{3}\right) ; V_{n-1}$ is the falling volume of the former, $\left(m^{3}\right)$.

Owing to the condition of the model, the initial falling height of the acceleration movement phase was not $0 \mathrm{~m}$ but the final height of the uniform motion phase. The volume can be calculated from the following equation:

$$
p_{n}=\frac{H-H_{m}-z_{n-1}}{H-H_{m}-z_{n}} \square p_{n-1}
$$

Where $H$ is the height of goaf, $(m) ; H_{m}$ is the final height of the uniform motion phase, $(m) ; z_{n}$ is the falling height of the acceleration movement phase, $(m) ; z_{n}$ is the latter falling height of the acceleration movement phase, $(m) ; z_{n-1}$ is the former falling height of the acceleration movement phase, $(m)$.

On the basis of the Newton's Law, the velocity and the falling height can be obtained:

$$
v_{n}=v_{n-1}+\left[g-\frac{\left(\mathrm{z}_{n}-z_{n-1}\right) \square p_{n-1}}{\rho_{d} N\left(H-H_{m}-z_{n}\right)}\right] \square t
$$

Because the outlet was linked with the goaf, the air shock wave in the outlet is applied to the Bernoulli equation [42], hence the air shock waves' velocity in the outlet can then be calculated from the following equation:

$$
v_{b}=\sqrt{\frac{2\left(p_{b n}-p_{b 0}\right)+v_{n}^{2} \rho_{n}}{g+\rho_{L}}}
$$

Where $v_{b}$ is the velocity of the outlet, $\left(m \cdot s^{-1}\right) ; p_{b n}$ is the later pressure of the outlet, $(P a) ; p_{b o}$ is the initial pressure of the outlet, $(P a)$. 
According to the on-site experiment, the area of the falling roof was smaller than the area of goaf. Based on the air quantity balancing law, the pressure of the outlet can be received:

$$
p_{b n}=\frac{S_{b}}{S-S_{a}+S_{b}} p_{n}
$$

Where $S_{a}$ is the sectional area of the falling roof, $\left(\mathrm{m}^{2}\right) ; S_{b}$ is the sectional area of the outlet, $\left(m^{2}\right)$.

Substituting Eq. (9) into Eq. (8), the following is get:

$$
v_{b}=\sqrt{\frac{2 \mathrm{~S}_{b}\left(p_{n}-p_{0}\right)+v_{n}^{2} \rho_{n}}{\left(g+\rho_{L}\right)\left(S-S_{a}+S_{b}\right)}}
$$

\section{Experiment}

\subsection{Experimental Set-up}

An experimental set-up was built to investigate the air shock wave induced by rock-fall in closed goaf, as shown in Fig 1. The experimental set-up consist of the air shock wave generator (Fig 2), the hot wire hot film Anemometer (HWFA) of IFA300 (Fig 3), data collection system and other components.

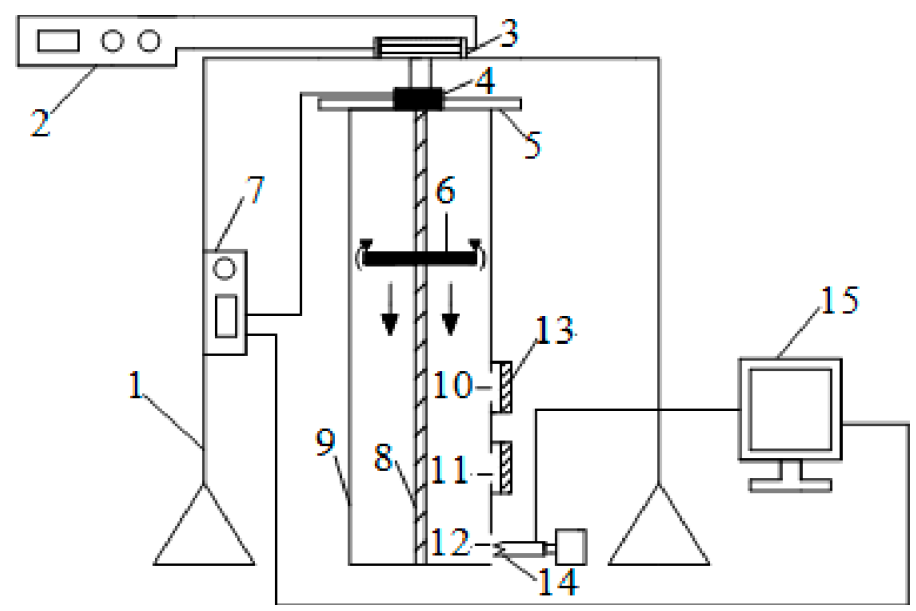

Figure 1. Experimental set-up. 
(1- the rigid frame, 2- alternating current power supply, 3- the hoist, 4-electromagnetic relays, 5capping, 6- iron-on salver, 7- control switch, 8- fixed link, 9- the tank, 10-3\# outlet tunnel, 11- 2\# outlet tunnel, 12- 1\# outlet tunnel, 13- valve, 14- the probe of HWFA of IFA300, 15- the data collection computer).

The air shock wave generator was made up of a tank, outlet, hoist and iron salver. The tank, with a diameter of $0.1 \mathrm{~m}$ and height of $1.25 \mathrm{~m}$, was cylinder-shaped and fixed on the ground. 1\# outlet was installed $0.05 \mathrm{~m}$ above the bottom of the tank with the square of $0.03 \mathrm{~m}$, and 2-3\# outlets were set up on its upside. 2\# outlet was $0.35 \mathrm{~m}$ away from the bottom of the tank, and 3\# outlet was $0.6 \mathrm{~m}$ away from the top of the tank. The outlet tunnel was linked to the outlet with the length of $0.1 \mathrm{~m}$. The upper of the tank was closed. The probe of HWFA of IFA300 was placed in the tunnel outlet. The iron-on salver was circular of $0.09 \mathrm{~m}$ and thickness of $0.01 \mathrm{~m}$, with the density $4500 \mathrm{Kg} \cdot \mathrm{m}^{-3}$. In order to verify effectiveness of the two-phase model, the experiments were carried out use three groups with different falling height which were $0.6 \mathrm{~m}, 0.9$ $m$ and $1.2 \mathrm{~m}$.

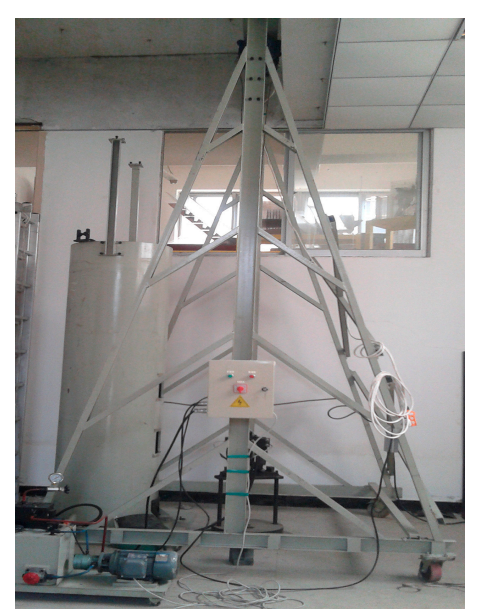

Figure 2. The air shock wave generator.

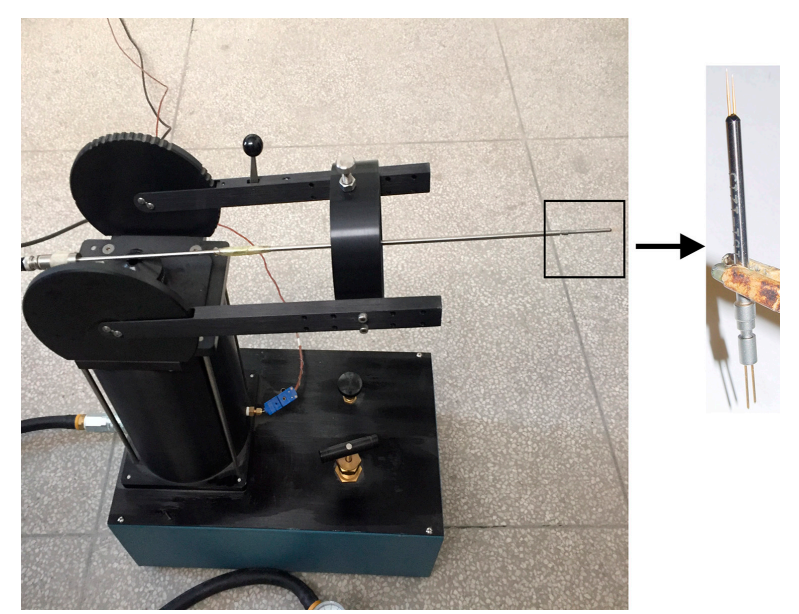

Figure 3. The hot wire hot film Anemometer of IFA300.

\subsection{Experimental Results and Discussion}

The velocity of the air shock wave after releasing the iron-on salver in the different falling heights were shown in Fig 4. As shown in Fig 4, the three curves 
followed the same trend, it was known that the velocity curves were composed of a straight line and a rapid growth curve. It could also be said that the model of twophase was possible to estimate the air shock waves' velocity.

At the phase of uniform motion, as the tank was closed, a huge pressure difference would be engendered in the tank with the iron-on salver's way down and prevented the air shock wave from the tank. At the phase of straight line, reducing the bound of pressure difference was a major factor in the rapid growth of velocity. Therefore, the realistic air shock wave was made up of the phase of acceleration movement and uniform motion. Meanwhile, the peak values of three velocity curves were not in direct proportion to its release heights, it is known that the closed goaf could reduce the air shock waves' hazards but not remove it.
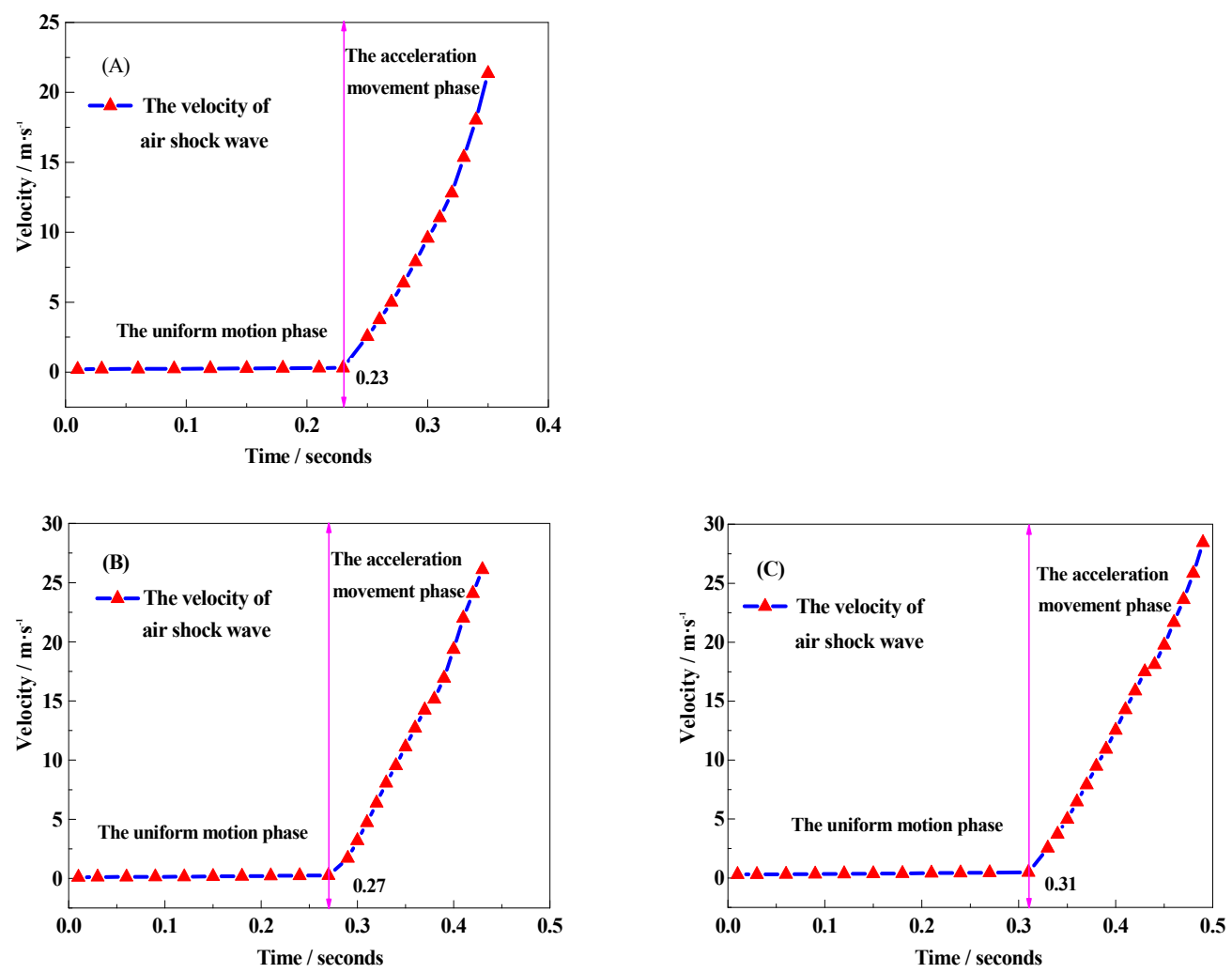

Fig 4. Relationship between velocity and time in the different falling heights.

(A) $0.6 \mathrm{~m}$. (B) $0.9 \mathrm{~m}$. (C) $1.2 \mathrm{~m}$. 
At the phase of uniform motion, as the tank was closed, a huge pressure difference would be engendered in the tank with the iron-on salver's way down and prevented the air shock wave from the tank. At the phase of straight line, reducing the bound of pressure difference was a major factor in the rapid growth of velocity. Therefore, the realistic air shock wave was made up of the phase of acceleration movement and uniform motion. Meanwhile, the peak values of three velocity curves were not in direct proportion to its release heights, it is known that the closed goaf could reduce the air shock waves' hazards but not remove it.

According to the experiment, huge pressure difference was generated with the iron-on salver falling. The air was regarded as incompressible due to the process of the experiment was transient. The upper part of the iron-on salver raised the zone of negative pressure and the bottom presented positive pressure, the outlet kept normal pressure [43]. The air of bottom would burst in the upside and outlet. If the pressure difference between upper apart and bottom could absorb enough air, the siphon phenomenon would form on the downside. As a result of this, the stage of uniform motion would appear. Otherwise, the stage of acceleration movement would turn up.

From Fig 4, it can be known that the velocity of $0.9 \mathrm{~m}$ and $1.2 \mathrm{~m}$ show the same trend as $0.6 \mathrm{~m}$, only that the phase of uniform motion is more obvious and the peak value is much higher. The velocity of $1.2 \mathrm{~m}$ release height was largest, followed by $0.9 \mathrm{~m}$ and $0.6 \mathrm{~m}$, were $21.3488 \mathrm{~m} \cdot \mathrm{s}^{-1}, 26.1003 \mathrm{~m} \cdot \mathrm{s}^{-1}$ and $28.4508 \mathrm{~m} \cdot \mathrm{s}^{-1}$ respectively, and the time of phase of uniform motion were $0.23 s, 0.27 s$ and $0.31 s$ respectively. The turning points of uniform motion phase and acceleration movement phase respectively were located $0.2645 \mathrm{~m}, 0.3645 \mathrm{~m}, 0.4805 \mathrm{~m}$ in the above release heights on account of Newton's Laws. From Eq.(6), the pressure difference was inverse proportional to the falling height. As a result of this, the phase of the acceleration 
movement gets enlarge. This indicates that the phase of acceleration movement is taking a larger portion and uniform motion is smaller when the height of rock-fall is higher. However, increasing the height of rock-fall was strengthening the role function time of the pressure difference. Hence, the higher falling roof was, the low the growth rate of the acceleration movements' phase. Because of occupied a larger portion, the higher falling roof was, the higher the air shock waves' velocity, but not in direct proportion to the falling roof.

\subsubsection{The Uniform Motion Phase}

From Fig 4, it could be seen that there was a linear relation between the height and time of the uniform motion phase, and the falling height. The relation between both variables could be expressed as:

$$
H_{m}=a H^{2}+b H+c
$$

Where $H_{m}$ corresponds to the height of the uniform motion phase, in meters $(m) ; a, b$ and $c$ are the parameters of the curve; and $H$ is the falling height, in meters $(m)$. The values for $a, b$ and $c$ for the uniform motion phase are $0.11025,0.19551$ and $0.0866761 m$ respectively, with a coefficient of determination $R^{2}$ equal to 0.99 .

\subsubsection{The Acceleration Movement Phase}

According to experimental set-up and Eq.(11), the coefficients for both conditions, the different falling heights were summarized in Table 1.

Table 1. The coefficients for acceleration movement phase

\begin{tabular}{lllllllllll}
\hline $\boldsymbol{H}(\boldsymbol{m})$ & $\boldsymbol{S}_{\boldsymbol{a}}\left(\boldsymbol{m}^{2}\right)$ & $\boldsymbol{S}_{b}\left(\boldsymbol{m}^{2}\right)$ & $\boldsymbol{\rho}_{d}\left(\mathrm{Kg} \cdot \boldsymbol{m}^{3}\right)$ & $\boldsymbol{r}(\boldsymbol{m})$ & $\boldsymbol{N}(\boldsymbol{m})$ & $\boldsymbol{p}_{0}(\boldsymbol{P a})$ & $\boldsymbol{\rho o}_{0}\left(\mathrm{Kg} \cdot \mathrm{m}^{3}\right)$ & $\boldsymbol{g}\left(\boldsymbol{m} \cdot \mathbf{s}^{2}\right)$ & $\boldsymbol{t}(\mathbf{s})$ & $\boldsymbol{H}_{\boldsymbol{m}}(\boldsymbol{m})$ \\
\hline $\mathbf{0 . 6}$ & 0.00636 & 0.0009 & 4500 & 0.045 & 0.01 & 103360 & 1.225 & 9.8 & 0.12 & 0.2645 \\
$\mathbf{0 . 9}$ & 0.00636 & 0.0009 & 4500 & 0.045 & 0.01 & 103360 & 1.225 & 9.8 & 0.16 & 0.3645 \\
$\mathbf{1 . 2}$ & 0.00636 & 0.0009 & 4500 & 0.045 & 0.01 & 103360 & 1.225 & 9.8 & 0.18 & 0.4805
\end{tabular}

Used to MATALAB to solve Eq.(1) to Eq.(10) by the above coefficients, the experimental values and theoretical values of the air shock waves' velocity in the 
outlet could be appearing on Fig 5. As shown in Fig 5, the experimental values and theoretical values followed the same trend.

The absolute errors between experimental results and theory analysis were shown in Fig 6, for different falling heights. The absolute errors were almost less than $10 \%$, and the absolute errors of cut-off velocity were $1.87 \%, 0.50 \%$ and $3.26 \%$ respectively. Because the initial velocity was too little and the external wind was existing, led to a large impact on absolute error of initial points. The higher the air shock waves velocity, the less the impact of external wind. As results of this, the prediction precision of the two-phase model was increased.
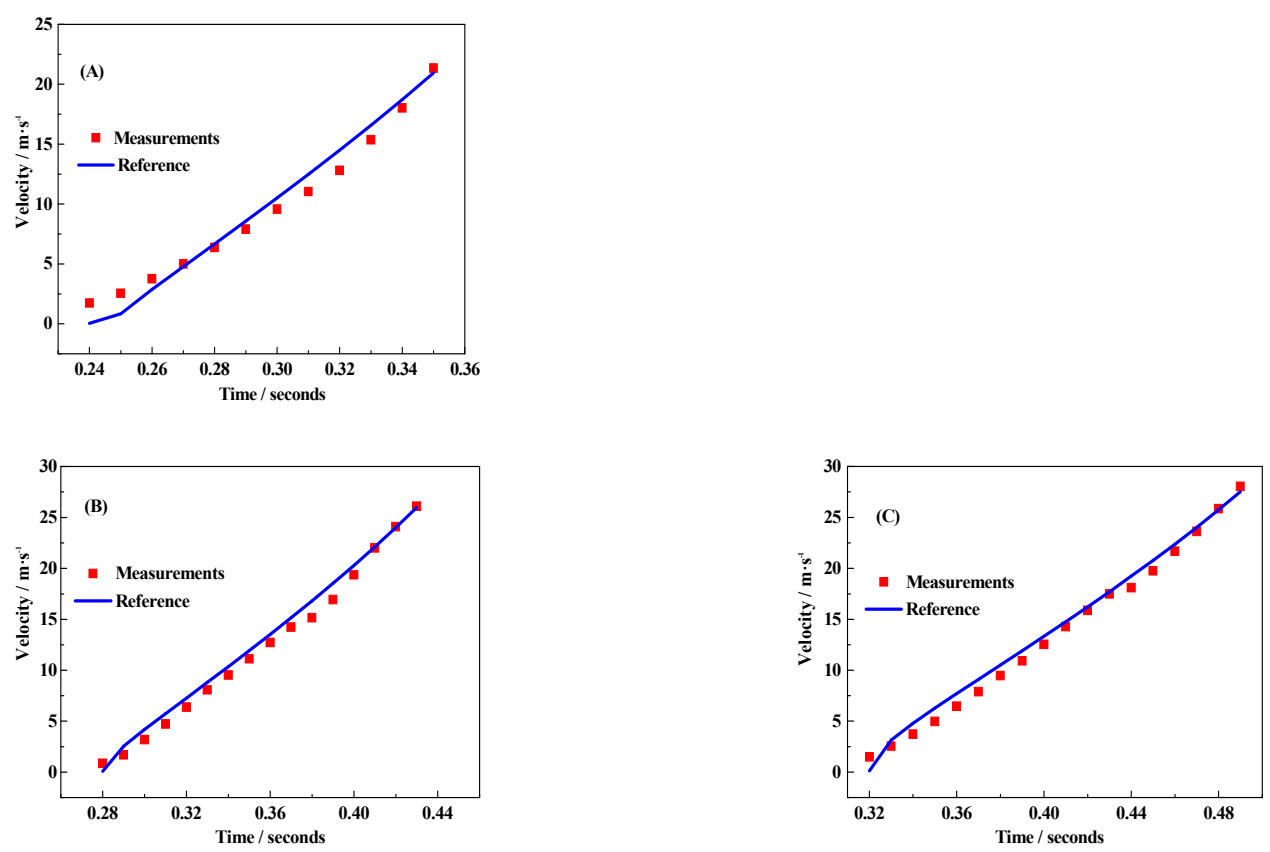

Figure 5. Velocity estimation using Eq. (10) versus experimental values in the different falling heights.

(A) $0.6 \mathrm{~m}$. (B) $0.9 \mathrm{~m}$. (C) $1.2 \mathrm{~m}$.

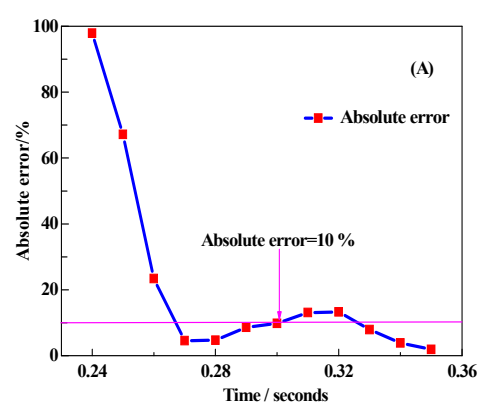



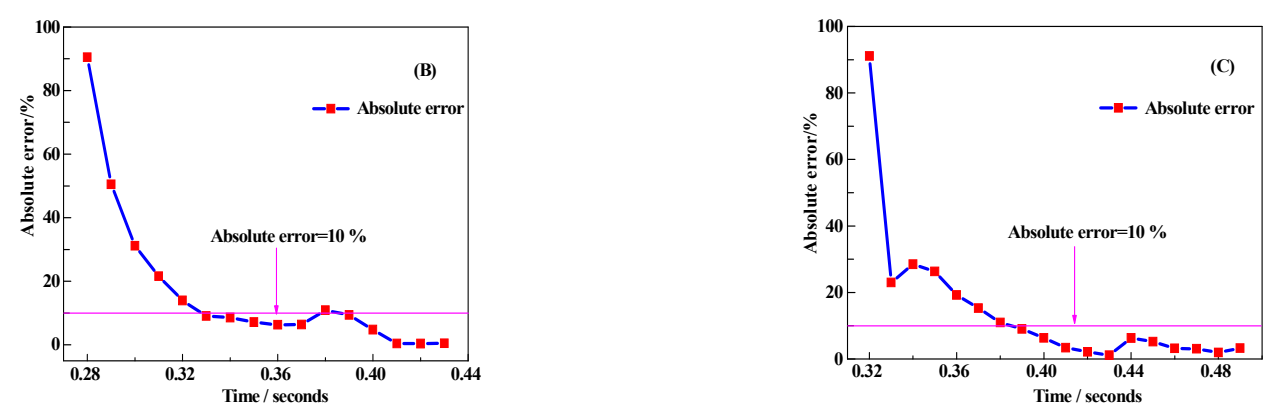

Figure 6. Absolute error between experimental results and theoretical analysis by different falling heights

(A) $0.6 \mathrm{~m}$. (B) $0.9 \mathrm{~m}$. (C) $1.2 \mathrm{~m}$.

This results show good agreement between experimental values and theory results. This demonstrates despite the small differences due to experimental error, that the model of two-phase provides an accurate way to evaluate it.

The calculation formula of the two-phase model follows:

$v_{b}= \begin{cases}0 & H_{m} \leq 0.11025 H^{2}+0.19551 H+0.0866761 \\ \sqrt{\frac{2 S_{b}\left(p_{n}-p_{0}\right)+v_{n}^{2} \rho_{n}}{\left(g+\rho_{L}\right)\left(S-S_{a}+S_{b}\right)}} & H_{m}>0.11025 H^{2}+0.19551 H+0.0866761\end{cases}$

\section{Numerical Simulation}

\subsection{Simulation Models}

The type of numerical model was designed using CFD and UDF according to a previous paper. And three different groups including $0.6 \mathrm{~m}, 0.9 \mathrm{~m}, 1.2 \mathrm{~m}$ were selected for the model verification. Group number indicated the height of rock-fall. For example, $0.6 \mathrm{~m}$ indicated that height of rock-fall was $0.6 \mathrm{~m}$. Then air outlet boundary of numerical model setting: PRESSURE-OUTLET; boundary conditions obtained from field. The rock-fall was defined as moving body, and used the UDF function to import compiled. 


\subsection{Simulation Results and Discussion}

The simulation results of velocity using three groups with different falling height were shown in Fig 7. As shown in Fig 7, the simulation results of air shock wave were composed of a straight line and a rapid growth curve. It can be known that the air shock waves' velocity of $0.9 \mathrm{~m}$ and $1.2 \mathrm{~m}$ show the same trend as $0.6 \mathrm{~m}$ from Fig 7 . Meanwhile, the time of the uniform motion phase were $0.32 s, 0.39 s$ and $0.46 s$ respectively, and the maximum velocity of three groups were $13.2089 \mathrm{~m} \cdot \mathrm{s}^{-1}, 19.6315$ $m \cdot s^{-1}$ and $25.0314 m \cdot s^{-1}$ respectively. Compared with the simulation values of the air shock wave with the same falling height in experimental results, the values in experimental results were larger than that in numerical simulations and the duration. time of the uniform motion phase were less than the numerical simulation results. Considering the objective impact force and energy were ignored, the influence of the pressure difference was enlarged. Consequently, the time of uniform motion phase got extended. Therefore, the location of the turning points were much lower than the experimental results'. The air was flushed to outlet immediately on the acceleration movement phase, considering the hypothesis of the air was identified as an incompressible gas. Hence, the ratio of numerical simulations' curves were much larger than the experimental results' on the acceleration movement phase.

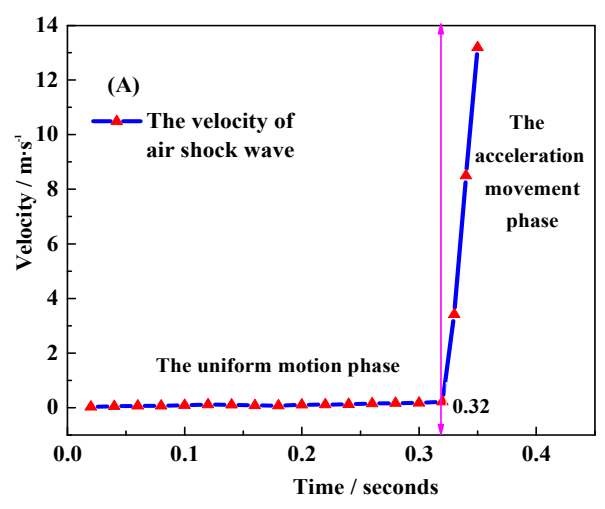



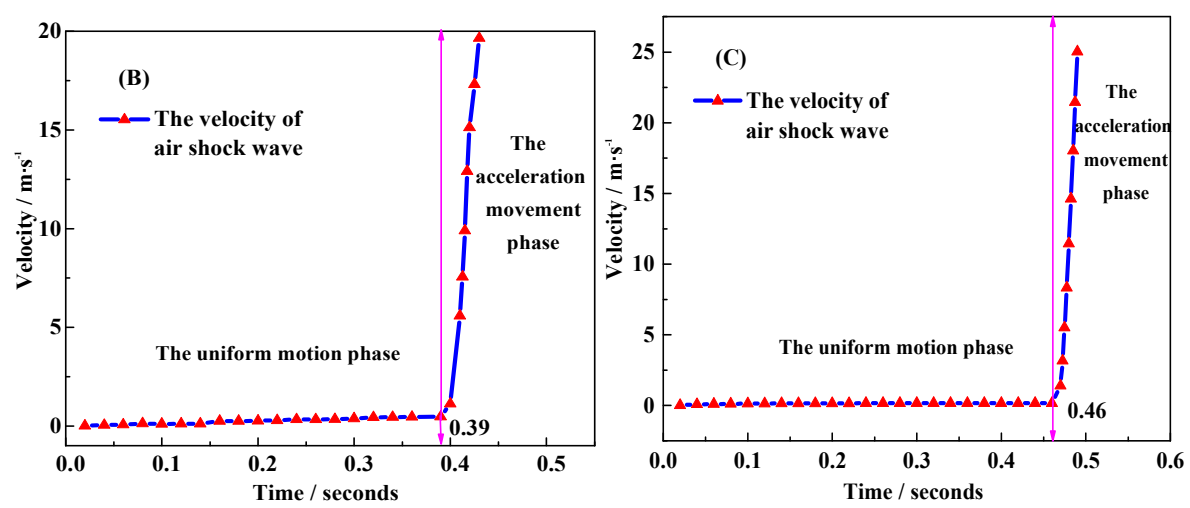

Figure 7. Simulation results of velocity using three groups with different falling roof. (A) $0.6 \mathrm{~m}$. (B) $0.9 \mathrm{~m}$. (C) $1.2 \mathrm{~m}$.

The velocity distribution at the turning point by three groups were shown in Fig 8. The maximum velocity were mostly distributed at the sides of the rock-fall, such as falling height with $0.6 \mathrm{~m}$ in Fig 8(A), $0.9 \mathrm{~m}$ height in Fig 8(B) and falling height with $1.2 m$ in Fig $8(\mathrm{C})$. Meanwhile, the values at upper part of rock-fall were larger than the values at bottom of rock-fall. The appearance of phenomenon might interpretation the role of pressure difference.

(A)

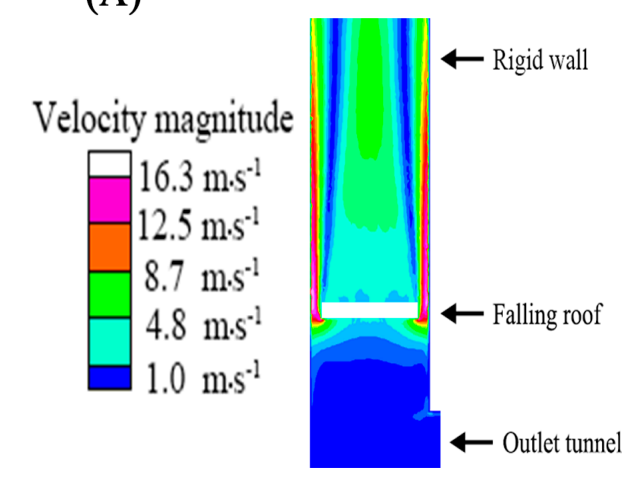

(B)
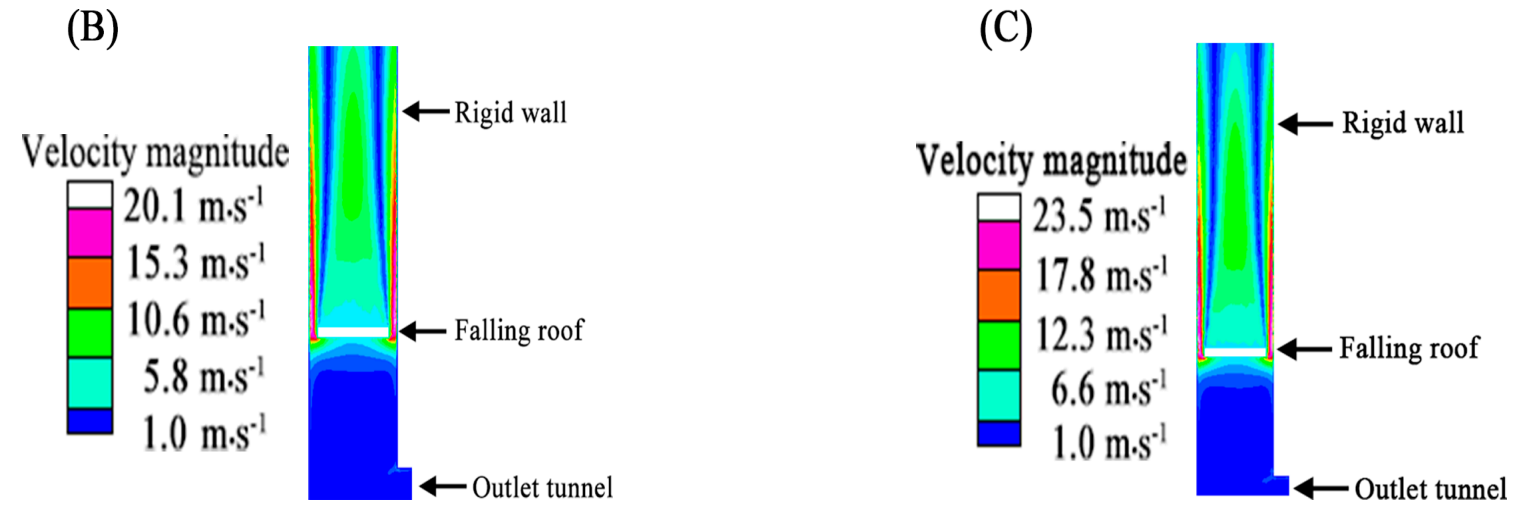
Figure 8. The velocity distribution at the turning point in three groups. (A) $0.6 m$. (B) $0.9 m$. (C) $1.2 \mathrm{~m}$.

This analysis shows that, the air shock wave induced by rock-fall was composed of the uniform motion phase and the acceleration movement phase. It verified the effectiveness of the two-phase model.

\section{Conclusions}

In this paper, we had proposed and verified the semi-empirical model of the air shock waves' velocity induced by rock-fall using theoretical analysis and experiments. We had evolved a two-phase model which was composed of the uniform motion phase(speed was close to $0 \mathrm{~m} \cdot \mathrm{s}^{-1}$ ) and the acceleration movement phase through theoretical analysis. Satisfactory agreement had surveyed in the field of the velocity and the variation trend of the air shock wave between the model and experimental results, which predicted the correctness and effectiveness of the model. By comparison between the experimental results using the groups with different falling roof, it was shown that the acceleration movement phase was taking a larger portion and the uniform motion phase was smaller when falling roof was higher. Meanwhile, the calculation formula of the two-phase model was obtained.

On the basis of the actual air shock wave, we had carried out CFD numerical simulation analysis of the air shock wave by different falling height. By comparing, the simulation results of different falling heights showed good agreements with theoretical analysis. 
This paper proposed a two-phase model to estimate the air shock waves' velocity induced by rock-fall in closed goaf which provided a method to estimate the air shock waves' velocity and designed the protective measures.

Supplementary Materials: Figure S1: Relationship between velocity and time in the different falling heights; Figure S2: Velocity estimation using Eq. (10) versus experimental values in the different falling heights; Figure S3: Absolute error between experimental results and theoretical analysis by different falling heights; Figure S4: Simulation results of velocity using three groups with different falling roof.

Acknowledgements: This research was supported by National Natural Science Foundation of China(No. 51534003, 51404065), National “Twelfth Five-Year" Plan for Science and Technology Support(No. 2013BAB02B08), the Fundamental Research Funds for the Central Universities(No. N140104008, N150104006).

Author Contributions: Fengyu Ren and Yang Liu conceived and designed the experiments; Jianli Cao performed the experiments; Rongxing $\mathrm{He}$ and Yuan $\mathrm{Xu}$ analyzed the data; Xi You and Yanjun Zhou contributed analysis tools; Yang Liu wrote the paper."

Conflicts of Interest: The authors declare no conflict of interest. 


\section{References}

1. Gao, F.; Wu, Y.; Stead, D.; Kang, H. Discrete element modelling of deformation and damage of a roadway driven along an unstable goaf - A case study. International Journal of Coal Geology. 2014, 127(7), 100-110.

2. Hao, T.X.; Jin, Z.C.; Li, F. Optimization of goaf gas drainage parameters based on numerical simulation studying fracture in overlying strata. Procedia Engineering. 2012, 43(9), 337-338.

3. Wang, G.; Cheng, W.; Xie, J. Field Test Research on Two-dimensional Gas Concentration and Temperature Distribution in the Goaf of Fully Mechanized Caving Face. Procedia Engineering. 2012, 43(43), 478-483.

4. Sobral, H.; Villagránmuniz, M.; Navarrogonzález, R.; Raga, A.C. Temporal evolution of the shock wave and hot core air in laser induced plasma. Applied Physics Letters. 2000, 77(20), 3158-3160.

5. Fujita, K.; Sato, S.; Abe, T.; Ebinuma, Y. Experimental Investigation of Air Radiation from Behind a Strong Shock Wave. Journal of Thermophysics \& Heat Transfer. 2015, 16(1), 77-82.

6. Tepeköylü, C.; Wang, F.S.; Kozaryn, R.; Albrecht-Schgoer, K.; Theurl, M.; Schaden, W.; et al. Shock wave treatment induces angiogenesis and mobilizes endogenous CD31/CD34-positive endothelial cells in a hindlimb ischemia model: Implications for angiogenesis and vasculogenesis. Journal of Thoracic \& Cardiovascular Surgery. 2013, 146(4), 971-8.

7. Chen, Q.K.; Ren, F.Y. Li, Q.W.; Tao, G.Q. [Study on the Technical Measures for Controlling the Roof-fall in Mined Area]. Metal Mine. 2002,316(10), 7-9. Chinese.

8. Zheng, H.C.; Song, C.Y.; Hu, L.; Xiao, G.; Li, M.; Zhang, X.J. [Simulation of air shock waves induced by large-scale roof caving in huge mined-out area](in). Journal 
of University of Science \& Technology Beijing. 2010, 32(3), 277-281. Chinese.

9. Dong, B.C. Study on The Prevention and Prediction of Surrounding Rock Caving Hazard in The 2\# Goaf Dongshenmiao Mine[Dissertations]. Baotou: Inner Mongolia University of Science and Technology; 2015. Chinese.

10. Janovsky, B.; Selesovsky, P.; Horkel, J.; Vejsa, L. Vented confined explosions in Stramberk experimental mine and AutoReaGas simulation. Journal of Loss Prevention in the Process Industries. 2006, 19(2-3), 280-287.

11. Rigas, F.; Sklavounos, S. Experimentally validated 3-D simulation of shock waves generated by dense explosives in confined complex geometries. Journal of Hazardous Materials. 2005, 121(1-3), 23-30.

12. Latter, R.; Similarity Solution for a Spherical Shock Wave. Journal of Applied Physics. 1955, 26(8), 954-960.

13. Jones, D.L. Strong Blast Waves in Spherical, Cylindrical, and Plane Shocks. 1961, 4(2), 1183-1184.

14. Xing, P.W.; Fu, Y.P.; Li, Z.J.; Song, X.M. [Coupling Model of Stope Roof with Hurricane Disaster and the Influence Analysis of Mining Height on Hurricane Velocity]. Journal of North University of China. 2010, 31(3), 228-231. Chinese.

15. Pennetier, O.; William-Louis, M.; Langlet, A. Numerical and reduced-scale experimental investigation of blast wave shape in underground transportation infrastructure. Process Safety \& Environmental Protection. 2015, 94, 96-104.

16. Sazhin, O. Liquid Flow Meter based on a Thermal Anemometer Microsensor. Journal of Applied Fluid Mechanics. 2016, 9(4), 1991-1996.

17. Khimji, H. inventor. Differential pressure anemometer: United States patent, US 8342036 B2[P]. 2013.

18. Grandpeix, J.Y.; Lafore, J.P. A Density Current Parameterization Coupled with 
Emanuel's Convection Scheme. Part I: The Models. Journal of the Atmospheric Sciences, 2016, 67(4), 881-897.

19. Ovink, R.; Lamers, A.P.G.G.; Steenhoven, A.A.; Hoeijmakers, H.W.M. A method of correction for the binormal velocity fluctuation using the look-up inversion method for hot-wire anemometry. Measurement Science \& Technology. 2001, 12(8), 12081213.

20. Joshi, J.B. Computational flow modelling and design of bubble column reactors. Chemical Engineering Science. 2001, 56(21), 5893-5933.

21. Rafique, M.; Chen, P.; Dudukovic``, M.P. COMPUTATIONAL MODELING OF GAS-LIQUID FLOW IN BUBBLE COLUMNS. Reviews in Chemical Engineering. 2006, 20(3-4), 225-375.

22. Dhotre, M.T.; Joshi, J.B. Two-Dimensional CFD Model for the Prediction of Flow Pattern, Pressure Drop and Heat Transfer Coefficient in Bubble Column Reactors. Chemical Engineering Research \& Design. 2004, 82(6), 689-707.

23. Ekambara, K.; Dhotre, M.T.; Joshi, J.B. CFD Simulations of Bubble Column Reactors: 1D, 2D and 3D Approach. Chemical Engineering Science. 2005, 60(23), 6733-6746.

24. Lapin, A.; Lübbert, A. Numerical simulation of the dynamics of two-phase gasliquid flows in bubble columns. Chemical Engineering Science. 1994, 49(21), 36613674.

25. Delnoij, E.; Lammers, F.A.; Kuipers, J.A.M.; Swaaij, W.P.M. Dynamic simulation of dispersed gas-liquid two-phase flow using a discrete bubble model. Chemical Engineering Science. 1997, 52(9), 1429-1458.

26. Lain, S.; Bröder, D.; Sommerfeld, M. Experimental and numerical studies of the hydrodynamics in a bubble column. Chemical Engineering Science. 1999, 54(21), 
4913-4920.

27. Buwa, V.V.; Deo, D.S.; Ranade, V.V. Eulerian-Lagrangian simulations of unsteady gas-liquid flows in bubble columns. International Journal of Multiphase Flow. 2006, 32(7), 864-885.

28. Hamm, V.; Sabet, B.B. Modelling of fluid flow and heat transfer to assess the geothermal potential of a flooded coal mine in Lorraine, France. Geothermics. 2010, 39 (39), 177-186.

29. Chanteloup, V.; Mirade, P.S. Computational fluid dynamics (CFD) modelling of local mean age of air distribution in forced-ventilation food plants. Journal of Food Engineering. 2009, 90(1), 90-103.

30. Zhang, H.; Pera, L.S.; Zhao, Y.; Sanchez, C.V. Researches and applications on geostatistical simulation and laboratory modeling of mine ventilation network and gas drainage zone. Process Safety \& Environmental Protection. 2014, 94, 55-64.

31. Zhu, Q.; Kato, S.; Murakami, S.; Lto, K. 3D-CFD analysis of diffusion and emission of VOCs in a FLEC cavity. Indoor Air. 2007, 17(3), 178-188.

32. Oey, R.S.; Mudde, R.F.; Akker, H.E.A.V.D. Sensitivity study on interfacial closure laws in two-fluid bubbly flow simulations. AIChE Journal. 2003, 49(7), 16211636.

33. Monahan, S.M.; Vitankar, V.S.; Fox, R.O. CFD predictions for flow-regime transitions in bubble columns. AIChE Journal. 2005, 51(7), 1897-1923.

34. Geng, S.; Jia, Z.; Zhan, J.; Xu, G.W. CFD modeling the hydrodynamics of binary particle mixture in pseudo-2D bubbling fluidized bed: Effect of model parameters. Powder Technology. 2016, 302, 384-395.

35. Lyubarskyy, P.;, Bartel, D. 2D CFD-model of the piston assembly in a diesel engine for the analysis of piston ring dynamics, mass transport and friction. Tribology 
International. 2016, 104, 352-368.

36. Xu, G.; Jong, E.C.; Luxbacher, K.D.; Mcnair, H.M. Effective utilization of tracer gas in characterization of underground mine ventilation networks. Process Safety \& Environmental Protection. 2016, 99, 1-10.

37. Spicka, P.; Dias, M.M.; Lopes, J.C.B. Gas-liquid flow in a 2D column: Comparison between experimental data and CFD modelling. Chemical Engineering Science. 2011, 56(21), 6367-6383.

38. Carino, F. inventor. Pragma facility and SQL3 extension for optimal parallel UDF execution: United States patent, US6067542[P]. 2000.

39. Qin, Z.Y.; Yuan, L.; Guo, H.; Qu, Q.D. Investigation of longwall goaf gas flows and borehole drainage performance by CFD simulation. International Journal of Coal Geology. International Journal of Coal Geology. 2015, 150, 51-63.

40. Travis, J.R.; Koch, D.P.; Xiao, J.; Xu, Z. Real-gas Equations-of-State for the

GASFLOW CFD code. International Journal of Hydrogen Energy. 2013 ,38(19), 8132-8140.

41. Hurly, J.J.; Schmidt, J.W.; Gillis, K.A. Virial equation of state and ideal-gas heat capacities of pentafluoro-dimethyl ether. International Journal of Thermophysics. 1997, 18(1), 137-159.

[42] Chen, G.; Krantz, S.G.; Ma, D.W.; Wayne, C.E.; West, H,H.The Euler-Bernoulli beam equation with boundary energy dissipation. Operator Methods for Optimal Control Problems. 1988, 67-96.

[43] Langefors, U.; Kihlström, B. The modern technique of rock blasting. Weinheim: Wiley; 1963.

(C) 2016 by the authors; licensee Preprints, Basel, Switzerland. This article is an open access article distributed under the terms and conditions of the Creative Commons by Attribution (CC-BY) license (http://creativecommons.org/licenses/by/4.0/). 